\title{
Poliovirus antibody titres, relative affinity, and neutralising capacity in maternal milk
}

\author{
S Zaman, B Carlsson, A Morikawa, S Jeansson, I Narayanan, K Thiringer, F Jalil, \\ L $\AA$ Hanson
}

\begin{abstract}
Varying titres of secretory IgA antibodies to poliovirus type 1 were found previously in the milk of unvaccinated, lactating Pakistani mothers during two different years, reflecting the antigenic exposure on mucosal membranes. To study further the changes in the extent and the form of antigenic exposure reflected in the human milk, human milk samples from Pakistani, Indian, Japanese, and Swedish mothers were collected. The quality and the neutralising capacity of the antibodies was also studied. Secretory IgA, IgG, and IgM antibodies to poliovirus type 1 were determined using enzyme linked immunosorbent assay (ELISA) and relative affinity was measured in ELISA by elution with potassium thiocyanide. Microneutralisation tests were also performed.

The higher secretory IgA antibody titres to poliovirus type 1 in the unvaccinated, naturally exposed Pakistani and Indian mothers' milk, compared with the Swedish and Japanese mothers, presumably reflect the epidemiological situation in these countries. Neutralising capacity and the relative antibody affinity seemed to be higher both in the Pakistani mothers and the group without natural exposure but only given inactivated poliovirus vaccine, that is the Swedish mothers, than the group meeting only live vaccine strains, that is the Japanese mothers.
\end{abstract}

Department of Social and Preventive Paediatrics, King Edward Medical College, Lahore,

Pakistan

$S$ Zaman

$F$ Jalil

Departments of Clinical Immunology Virology, and Paediatrics,

University of Göteborg,

Sweden

B Carlsson

$\mathrm{S}$ Jeansson

K Thiringer

L $\AA$ Hanson

Department of

Paediatrics,

University of Gunma,

Maebashi,

Japan

A Morikawa

Molchand Kharaiti

Hospital,

New Delhi,

India

I Narayanan

Correspondence to:

Dr Zaman.

Accepted 13 August 1992
(Arch Dis Child 1993;68:198-201)

In our previous study we found varying levels of secretory IgA antibodies to poliovirus type 1 in the milk of lactating, unvaccinated mothers living in the poor urban slum areas of Lahore, Pakistan. ${ }^{1}$ Secretory IgA antibodies in the milk of these mothers apparently reflect antigenic exposure on mucosal membranes, especially in the gut, and hence may follow the changes in the extent and form of antigenic exposure. ${ }^{2-9}$

The neutralising antibodies in the milk to poliovirus have usually been assumed to be primarily secretory IgA antibodies as suggested by earlier observations with isolated and even degraded secretory IgA. ${ }^{10}$ The poliovirus antibody titres in colostrum from mothers in Lahore, determined with the enzyme linked immunosorbent assay (ELISA), were high as was the neutralising capacity. ${ }^{1}$ This may be of special interest as in many developing countries live, oral poliovirus vaccine (OPV) is now given already at or soon after birth (Expanded Programme on Childhood Immunisation, Pakistan, interprovincial immunisation cover- age evaluation and disease surveillance 1987, unpublished $)^{11}$ and interference between virus and milk antibodies could occur if the infant is breast fed. ${ }^{12} 13$

Moreover, several studies have reported protection provided by breast milk against various enteric infections, ${ }^{1-18}$ reflecting not only the function of the amount of specific secretory $\operatorname{IgA}$ antibodies present but most likely also relating to the quality of the antibodies, for example avidity. ${ }^{19}$ This may have future implications in optimally using the vaccines in childhood immunisations in the developing countries.

This study was conducted in order to determine the presence, titres, and relative affinity of secretory $\operatorname{IgA}$ antibodies to poliovirus type 1 as well as neutralising capacity in the colostral and mature milk samples from Pakistan, India, Japan, and Sweden, where the extent and nature of exposure of the mothers to poliovirus varies.

\section{Subjects and methods}

STUDY POPULATIONS

This study was performed with breast milk samples from four groups of mothers. (1) Unvaccinated Pakistani mothers who were living in an area still endemic for poliomyelitis, but presently with almost $80 \%$ infants fully vaccinated from birth onwards using OPV. ${ }^{11} 20$ (2) Unvaccinated mothers from India-where poliomyelitis is still endemic and $45 \%$ of infants are presently vaccinated using OPV. ${ }^{11}$ (3) OPV vaccinated mothers in Japan-where poliomyelitis does not exist and only OPV is used for vaccinations. ${ }^{11}$ (4) Swedish mothers vaccinated exclusively with inactivated poliovirus vaccine (IPV)-where poliomyelitis as well as circulation of poliovirus in the community has been prevented. ${ }^{21}$

Nine samples of colostrum from Pakistani mothers living in the poor urban slum area of Lahore were obtained (mean day of collection was three days after delivery). Ten, eight, and 14 samples of colostrum each were obtained from the Indian, Japanese, and Swedish mothers respectively (mean day of collection was three days after delivery). The Indian mothers came from a poor section of New Delhi.

Mature milk samples were also collected from 13 Pakistani, 14 Japanese, and 15 Swedish lactating mothers between 13 to 360 days of lactation. The milk samples were obtained directly in plastic tubes after gentle expression of the breasts. The samples were kept at $-20^{\circ} \mathrm{C}$ until transported on dry ice. All milk samples were analysed at the same time period. 


\section{ANTIBODY DETERMINATIONS}

The samples of milk and colostrum were thawed and centrifuged twice to eliminate fat and cells. ELISA was performed as already described. ${ }^{22}{ }^{23}$ Poliovirus type 1 antigen produced by the Rijksinstituut voor Volkgezondheid en Milieuhygiene, Bilthoven, the Netherlands was used for coating microtitre plates. Rabbit antisera to $\alpha, \gamma$, and $\mu$ chains (Dakopatts AS) conjugated to alkaline phosphatase, and sheep antiserum against secretory component (Seward Labs) were used for reading the samples tested in four 10-fold dilutions. Titres were expressed as the interpolated reciprocal reading giving an absorption of 0.2 above background at $405 \mathrm{~nm}$.

Antibody avidities were determined in ELISA, ${ }^{24}{ }^{25}$ where potassium thiocyanide (diluted in phosphate buffered saline containing $0.05 \%$ Tween 20 ) was used in eight different concentrations ranging from $0.25 \mathrm{M}$ to $4 \mathrm{M}$ to elute the antibodies bound to the antigen on the solid phase. All samples were first diluted to similar antibody activity (a reading of $0.6-0.8$ optical density for uneluted samples). Relative affinity index was calculated as the molarity of potassium thiocyanide where $50 \%$ of the antibodies were eluted.

Neutralisation titres were determined in a modified technique using microtitre plates with poliovirus type 1 virus. Starting dilution was $1: 10 .^{26} 27$

\section{STATISTICAL ANALYSIS}

$\log _{10}$ transformations were done on the reciprocal ELISA titres. Neutralisation titres were given as geometric mean titres. These means were compared using Wilcoxon's rank sum test. The statistical significance was chosen at the 0.05 level with a two tailed test. ${ }^{28}$

\section{Results}

The reciprocal ELISA titres of IgA, IgG, and

Table 1 Mean (2SEM) secretory IgA antibody titres against poliovirus type 1 antigen in the samples of colostrum with number of positive samples out of total for IgG and IgM in mothers from different countries

\begin{tabular}{|c|c|c|c|c|}
\hline \multirow[t]{2}{*}{ Country } & \multirow{2}{*}{$\begin{array}{l}\text { Mean (range) } \\
\text { days post- } \\
\text { partum }\end{array}$} & \multicolumn{3}{|l|}{ ELISA titres* } \\
\hline & & $I g A^{*}$ & $I g G t$ & $I g M t$ \\
\hline $\begin{array}{l}\text { Pakistan }(n=9) \\
\text { India }(n=10) \\
\text { Japan }(n=8) \\
\text { Sweden }(n=14)\end{array}$ & $\begin{array}{l}2 \cdot 5(2-4) \\
3 \cdot 0(3) \\
3 \cdot 0(3-4) \\
3 \cdot 0(2-3)\end{array}$ & $\begin{array}{l}4 \cdot 28(3 \cdot 98-4 \cdot 57) \\
4 \cdot 65(4 \cdot 22-5 \cdot 05) \\
3.02(2 \cdot 25-3 \cdot 80) \\
3 \cdot 06(2 \cdot 66-3 \cdot 53)\end{array}$ & $\begin{array}{l}1 / 9 \\
0 / 10 \\
2 / 8 \\
1 / 14\end{array}$ & $\begin{array}{l}9 / 9 \\
6 / 10 \\
1 / 8 \\
2 / 14\end{array}$ \\
\hline
\end{tabular}

*Titres as assessed by ELISA expressed as $\log _{10}$. Comparison of Indian mothers in secretory IgA titres with Pakistani mothers $(>0.05)$ and with Japanese and Swedish mothers $(p<0.01)$ using Wilcoxon's rank sum test.

†Number of samples positive among the total number of samples.

Table 2 Comparison of antibodies to poliovirus type 1 in mature milk from mothers from different countries representing different forms and extent of antigen exposure

\begin{tabular}{llllll}
\hline Country & $\begin{array}{l}\text { No of } \\
\text { mothers }\end{array}$ & $\begin{array}{l}\text { Mean } \\
\text { (range) days }\end{array}$ & Mean titres & & \\
\cline { 4 - 6 } & & $13 A$ & $3 \cdot 53^{*}(2 \cdot 81-4 \cdot 25)^{* *}$ & ND & ND \\
\hline Pakistan & 13 & $148(42-222)$ & $2 \cdot 14(1 \cdot 98-2 \cdot 31)$ & $4 / 15$ & $0 / 15$ \\
Japan & 15 & $200(30-360)$ & $2 \cdot 16(1 \cdot 88-2 \cdot 45)$ & $2 / 14$ & $2 / 14$ \\
Sweden & 14 & $36(13-67)$ & &
\end{tabular}

* Significantly higher than in Japanese and Swedish samples $(p<0.05)$

**2SEM are presented for mean IgA titres.

ND=not done.
IgM in samples of colostrum against poliovirus type 1 are shown in table 1 . The mean IgA titres were the highest in the Pakistani and Indian samples and were significantly higher than the Swedish and Japanese colostral samples $(p<0.01)$. IgG antibodies were rarely found. All the Pakistani mothers had high IgM titres. Six out of 10 Indian and only 2/14 Swedish and 1/8 Japanese mothers had detectable IgM antibodies (table 1).

The mature milk samples from the Pakistani mothers showed the highest mean IgA titres to poliovirus type 1 compared with the Swedish or the Japanese milk samples $(p<0 \cdot 05)$. IgG antibodies were detected in a few Swedish and Japanese samples. IgM antibodies were rarely found in the Swedish or Japanese milk samples, and they were not determined in Pakistani milk samples (table 2).

The relative affinity index calculated for mature milk antibodies from the Swedish mothers was significantly higher than in the Swedish colostrum samples $(p<0 \cdot 001)$. Swedish mature milk samples also had a higher affinity index than the Japanese mature milk $(\mathbf{p}<0.005)$. No other significant differences were seen between or within the groups (table 3 ).

Geometric means of neutralisation titres to poliovirus type 1 were the highest in the Pakistani samples of colostrum compared with the Indian $(p<0.05)$, Swedish $(p<0.05)$, or Japanese samples, which had very low neutralisation titres. The mean neutralisation titres were similar in the Pakistani and the Swedish mature milk samples and were very low in all the samples from the Japanese mothers (table 4).

Table 3 Mean (range) avidity index for IgA antibodies in milk expressed as molarity of potassium thiocyanide giving $50 \%$ antibody activity of uneluted sample

\begin{tabular}{lll}
\hline Country & Colostrum & Mature milk \\
\hline Pakistan & $0 \cdot 85(0 \cdot 25-1 \cdot 53)$ & $1 \cdot 04(0 \cdot 45-1 \cdot 60)$ \\
[n] & {$[9]$} & {$[9]$} \\
Japan & $0 \cdot 82(0 \cdot 1-1 \cdot 38)$ & $0 \cdot 77(0 \cdot 06-1 \cdot 38)$ \\
[n] & {$[8]$} & {$[15]$} \\
$\begin{array}{c}\text { Sweden } \\
\text { [n] }\end{array}$ & $0 \cdot 61(0 \cdot 1-1 \cdot 4)$ & $1 \cdot 59^{*}(0 \cdot 8-2 \cdot 50)$ \\
\hline
\end{tabular}

${ }^{*}$ Swedish mature milk significantly higher than Swedish colostrum $(p<0.001)$ and Japanese mature milk $(p<0.005)$.

Table 4 Neutralisation titres expressed as geometric mean titres representing the neutralising capacity of the samples of colostrum and mature milk in mothers from different countries

\begin{tabular}{lll}
\hline Country & Neutralisation titres & \\
\cline { 2 - 3 } & Colostrum & Mature milk \\
\hline Pakistan & $6 \cdot 0^{* *}$ & $4 \cdot 0+$ \\
[n] & {$[9]$} & {$[13]$} \\
India & $4 \cdot 0$ & ND \\
[n] & {$[10]$} & $<3 \cdot 0$ \\
Japan & $<3 \cdot 0$ & {$[15]$} \\
[n] & {$[8]$} & $4 \cdot 0 \#$ \\
Sweden & $3 \cdot 0$ & {$[14]$} \\
[n] & {$[14]$} & \\
\hline
\end{tabular}

${ }^{*}$ Neutralisation titres expressed as geometric mean titres. ** Showing significant differences between India, Pakistani, and ** Showing significant differences

Swedish colostrum $(\mathbf{p}<0.05)$. tGeometric mean titres (SD) $3.67(0.64)$ and $3.67(0.43)$ for Pakistani and Swedish mature milk samples $(p>0.05)$ $\mathrm{ND}=$ not done. 


\section{Discussion}

Human milk contains a variety of antibodies to intestinal microbes to which the mother is exposed. ${ }^{29}$ The milk antibodies against salmonella and shigella reflected well the higher extent of exposure of the Guatemalan compared with Swedish mothers. ${ }^{3}$ A different antibody response to cholera vaccination and to live and killed poliovirus vaccinations was seen in Pakistani and Swedish mothers ${ }^{56}$ as another illustration of the connection between intestinal exposure and milk antibody response.

The significantly higher secretory IgA antibody titres in the mature Pakistani milk samples compared with Japanese and Swedish milk samples may suggest that exposure is maintained throughout the lactation period in the Pakistani mothers. The lower values in the Japanese and the Swedish mothers presumably reflect the result of a long term immunological memory because their exposure to the poliovirus in the form of vaccine had taken place years earlier. ${ }^{2}$

The present data agree with previous suggestions that milk antibodies may reflect the epidemiological situation in a community. ${ }^{12}$ In India and Pakistan wild as well as vaccine poliovirus strains are still in circulation, ${ }^{11}{ }^{20}$ and nationwide vaccinations of children against poliomyelitis are being done using OPV. As a result, the Indian and Pakistani mothers had higher secretory IgA antibody titres against poliovirus type 1 in their milk than the Japanese and Swedish mothers. The fact that the Pakistani mothers had significantly higher mean secretory IgA antibody titres $(p<0.01)$ compared with the Japanese and Swedish mothers presumably illustrates the high endemicity of poliomyelitis in Pakistan. ${ }^{11}$ The Japanese mothers are presently exposed only to vaccine strains as no cases of acute poliomyelitis have been reported since $1981^{11}$ and OPV has been the vaccine used since $1955 .{ }^{11}$ In contrast, the only permitted vaccine in Sweden has been IPV since 1955, eliminating wild as well as vaccine virus strains during the late $1970 \mathrm{~s}^{21}$ The secretory IgA antibody titres to poliovirus type $\overline{1}$ may still appear in this situation as repeated doses of IPV can induce a secretory IgA response. ${ }^{23} 29$

The secretory IgA antibodies occurring after repeated IPV also seemed to be of higher avidity than those after both natural exposure and OPV. The avidities of the antibodies in the Swedish mothers even increased during lactation. It seems that there can be quite variable patterns in the milk antibody avidities as we have been able to demonstrate both decreases and increases as lactation goes on. Milk from Costa Rican as well as Swedish mothers showed decreasing avidities against Escherichia coli $\mathrm{O}$ antigens comparing colostrum and mature milk. ${ }^{30}$ Earlier, we were not able to see such avidity decreases in antibodies to $E$ coli $O$ antigens to Pakistani mothers. ${ }^{25}$ It was also remarkable that the Swedish mothers had higher neutralising titres than the Japanese mothers. It is not known whether this can be related to the higher avidity of the Swedish milk antibodies.

The higher antibody avidity in the secretions indicates a more mature immune response produced after continuing antigen exposure. ${ }^{19} 25$ Thus IPV can probably give rise to memory cells, which then can migrate to the lactating mammary gland many years after the vaccination. Nutritional status, repeated infections, and a possible genetic mechanism may be responsible in determining the antibody avidity. ${ }^{19} 3132$ However different routes of antigenic exposures seem to be a more prominent factor in our study.

The low neutralisation titres in the Japanese colostrum samples indicate that natural exposure and repeated IPV vaccinations can induce a better neutralising antibody response in secretions than vaccinations with live vaccines. ${ }^{33}$ Also, a higher avidity index can be obtained by repeated vaccinations with IPV.

This study was supported by grants from the Swedish Agency for Research Cooperation with Developing Countries; the Ellen, Walter and Lennart Hesselman Foundation for Scientific research; and the Faculty of Medicine, University of Göteborg and the Swedish Medical Research Council (No 215).

We wish to thank Eeva Nisshagen, Ingela Karlsson, and AnnMarie Månquist for skilfull technical assistance and Mrs Surraiya for help in the field work.

1 Zaman S, Carlsson B, Jalil F, Jeansson S, Mellander L, Hanson $L \AA$. Specific antibodies to poliovirus type 1 in breastmilk of naturally exposed mothers before and seven years after start of community-wide vaccination of their years after start of community-wide vaccination of their
infants with live, oral poliovirus vaccine. Acta Paediatr Scand 1991;80:1174-82.

2 Hanson LA, Carlsson B, Cruz JR, et al. Immune response in the mammary gland. In: Ogra PL, Dayton D, eds. Immunology of breastmilk. New York: Raven Press, 1979: 145-57.

3 Cruz JR, Carlsson B, Hofvander Y, Holme DT, Hanson LÅ. Studies of human milk. II. Concentration of antibodies against salmonella and shigella in milk of women from different populations and the daily intake of their breast-fed different populations and the daily intake of thei
infants. Acta Paediatr Scand 1985;74:338-41.

4 Cruz JR, Carlsson B, Garcia B, et al. Studies of humanmilk. III Secretory IgA quantity and antibody levels against Escherichia coli in colostrum and milk from underprivileged and privileged mothers. Pediatr Res 1982;16:272-6.

5 Svennerholm A-M, Hanson LA, Holmgren J, Lindblad BS, Nilsson BS, Qureshi F. Different secretory IgA antibody response to cholera vaccination in Swedish and Pakistani women. Infect Immunol 1980;30:427-30.

6 Svennerholm A-M, Hanson LA,, Holmgren J, et al. Antibody responses to live and killed polio vaccines in Pakistani and responses to live and killed polio vaccines in Pak

7 Carlsson B, Ahlstedt S, Hanson LA, Lidin-Janson G, Lindblad BS, Sultana R. Escherichia coli O antibody content in milk from healthy Swedish mothers and mothers from a very low socio-economic group of a developing country. Acta Paediatr Scand 1976;65:417-23.

8 Mestecky J. The common mucosal immune system and current strategies for induction of immune responses in external secretions. F Clin Immunol 1987;7:265-75.

9 Czerkinsky C, Prince SJ, Michalek SM, et al. IgA antibodyproducing cells in peripheral blood after antigen ingestion:
Evidence for a common mucosal immune system in Evidence for a common mucosal immune sys
humans. Proc Natl Acad Sci USA 1987;84:2449-53.

10 Hanson LA, Johansson BG. Immunological studies of human milk. In: MacKenzie HA, ed. Milk proteins. Vol I. New York: Academic Press, 1970:45-123.

11 Expanded Programme on Childhood Immunisation. Global situation-poliomyelitis. Newsletter EPI July 1987.

12 Plotkin SA, Katz M, Brown RE, Pagano JS. Oral poliovirus vaccination in newborn African infants. The inhibitory effect of breast feeding. Am $\mathcal{Y}$ Dis Child 1966;111:27-30.

13 Warren RJ, Leparo M, Glem EB, Frederick CR. The relationship of maternal antibody, breastfeeding and age to susceptibility of newborn infants to infection with attenuated poliovirus. Pediatrics 1964;33:4-13.

14 Glass RE, Svennerholm A-M, Stoll B, et al. Protection against cholera in breast-fed children by antibodies in against cholera in breast-fed children by a
breastmilk. N Engl f Med 1983;308:1389-92.

15 Hielt K, Grauballe PC, Nielson OH, Schiotz PO, Krasilnikoff PA. Rotavirus antibodies in the mother and Krasilnikoff PA. Rotavirus antibodies in the mother and 414-20.

16 Snodgrass DR, Fahey KJ, Well PW, Campbell I, Whitelaw A. Passive immunity in calf rotavirus infections: maternal vaccination increases and prolongs immunoglobulin Gl antibody secretion in milk. Infect Immunol 1980;28:344-9.

17 Dimmock NJ. Mechanisms of neutralisation of animal viruses. F Gen Virol 1984;65:1015-22.

18 Isaacs CE, Thormer H, Pessalano T. Membrane-disruptive effect of human milk: inactivation of enveloped viruses. f Infect Dis 1986;154:966-71.

19 Steward $M W$. The biological significance of antibody affinity. 
20 Grant JP. Immunization: a surge forward. The state of the world's children 1986. United Nations Children's Fund (UNICEF). New York: Oxford University Press, 1986: 1-20.

21 Böttiger $\mathbf{M}$. Long-term immunity following vaccination with killed poliovirus vaccine in Sweden, a country with no circulating poliovirus. Rev Infect Dis 1984;6:548-51.

22 Ahlstedt S, Carlsson B, Hanson LA, Kaijser B, MattsbyBaltzer M, Sohl Âkerlund A. Application of the ELISA for determination of immunoglobulin class-specific E coli determination of immunoglobulin class-spec

23 Carlsson B, Zaman S, Mellander L, Jalil F, Hanson LÅ. Secretory and serum immunoglobulin class-specific antiSecretory and serum immunoglobulin class-specific anti-
bodies to poliovirus after vaccination. $\mathcal{F}$ Infect Dis 1985; 152:1238-44.

24 Pullen GR, Fitzgerald MC, Hosking CS. Antibody avidity determination by ELISA using thiocynate elution. I Immunol Methods 1986;86:83-7.

25 Roberton DM, Carlsson B, Coffman K, et al. Avidity of IgA antibodies to Escherichia coli polysaccharride and diphtheria and Pakistani mothers. Scand F Immunol 1988;28:783-9.

26 Halliburton G, Becker ME. The use of hepesbuffer in microtissue culture plates for routine enterovirus diagnosis. tissue culture plates for routine enteroviru

27 Grillner L, Blomberg J. Haemolysis in gel and neutralization tests tor determination of antibodies to mumps virus. $\mathcal{F}$ Clin Microbiol 1976;4:11-5.

28 Colton T. Statistics in medicine. 1st Ed. Boston: Little, Brown, 1974.

29 Hanson LA, Carlsson B, Jalil F, et al. Antiviral and antibacterial factors in human milk. In: Hanson LA, ed. Biology of human milk. Vol 15. New York: Nestle Ltd, Vevey/Raven Press, 1988:141-57.

30 Hanson LÅ, Jalil F, Ashraf R, et al. Characteristics of human milk antibodies and their effect on the offspring in relation to the epidemiology of breastfeeding and infections in a developing country. Proceedings of NIH meeting. Immuno$\log y$ of milk and the neonate. 1991 (in press)

31 Passwell JH, Steward MW, Soothill JF. The effects of protein malnutrition on macrophage function and the amount and affinity of antibody response. Clin Exp

32 Steward MW, Petty RE. Evidence for the genetic control of antibody affinity from breeding studies with inbred mouse strains producing high and low affinity antibodies. Immuse strains producing high
$\log y$ 1976;30:789-97.

33 Hanson LA, Ahlstedt S, Carlsson B, et al. Effects of cholera and poliovirus immunizations upon specific antibodies in and poliovirus immunizations upon specific antibodies in
human milk. In: Hamosh $M$, Goldman $A$, eds. Human human milk. In: Hamosh M, Goldman A, eds. Human
lactation 2. Maternal environmental factors. New York: Raven Press, 1986:541-5. 